\title{
A EDUCAÇÃO AMBIENTAL CONSTITUÍDA NA PRÁXIS DO TRABALHO TÉCNICO SOCIAL: TEORIA E PRÁTICA NO CONTEXTO DE CONFLITO SOCIOAMBIENTAL NO PROCESSO DE EXPANSÃO DE ÁREA PORTUÁRIA NO MUNICÍPIO DO RIO GRANDE
}

\author{
Anderson Pires Souza ${ }^{1}$ \\ Thaís Gonçalves Saggiomo ${ }^{2}$ \\ Lucia de Fátima SocoowskiAnello ${ }^{3}$
}

\begin{abstract}
RESUMO
Objetivamos neste artigo desenvolver uma estrutura teórico/reflexiva entorno da Educação Ambiental na práxis do trabalho técnico social, inserido no contexto de conflitos socioambientais no processo de expansão portuária e reassentamento habitacional das famílias do Bairro Getúlio Vargas, no Município do Rio Grande/RS. Para análise buscamos a fundamentação teórica na teoria crítica, traçando metodologicamente as reflexões a partir de uma estrutura baseada na revisão bibliográfica e na análise documental. Dentre as análises, destacamos a importância do trabalho educativo fundamentar-se na perspectiva da Educação Ambiental crítica e transformadora, articulando em sua proposição metodológica a teoria freireana, no sentido de reafirmar a educação como ato político e o diálogo como instrumento essencial ao desvelamento da realidade.
\end{abstract}

Palavras-chave: Educação Ambiental Crítica; Conflito socioambiental; Trabalho Técnico Social.

\footnotetext{
${ }^{1}$ Graduado em Letras Português/Francês e Pedagogia. Mestrando em Educação Ambiental na Universidade Federal do Rio Grande.

${ }^{2}$ Educadora. Pedagoga. Mestre em Educação. Doutoranda em Educação Ambiental

${ }^{3}$ Licenciada em Educação Física. Mestre e Doutora em Educação Ambiental. Docente no Programa de Educação Ambiental.
} 


\title{
THE ENVIRONMENTAL EDUCATION CONSTITUTED IN THE PRAXIS OF SOCIAL TECHNICAL WORK: THEORY AND PRACTICE IN THE CONTEXT OF SOCIOENVIRONMENTAL CONFLICT IN THE PROCESS OF EXPANSION OF PORT AREA IN THE MUNICIPALITY OF RIO GRANDE
}

\begin{abstract}
The objective of this article is to develop a theoretical / reflexive framework surrounding Environmental Education in the practice of social technical work, inserted in the context of socioenvironmental conflicts in the process of port expansion and housing resettlement of the families of the Getúlio Vargas neighborhood, in the Municipality of Rio Grande / RS. For analysis we seek the theoretical basis in the critical theory, tracing methodologically the reflections from a structure based on the bibliographical revision and the documentary analysis. Among the analyzes, we emphasize the importance of educational work based on the perspective of critical and transformative Environmental Education, articulating in its methodological proposition the Freirean theory, in the sense of reaffirming education as a political act and dialogue as an essential instrument to the unveiling of reality.
\end{abstract}

Key-words: Critical Environmental Education. Socioenvironmental conflict. Social Work.

\section{INTRODUÇÃO}

O presente artigo trata de uma investigação sobre o desenvolvimento do Trabalho Técnico Social executado na perspectiva da Educação Ambiental crítica em um contexto do reassentamento de moradores de uma ocupação urbana em área de expansão portuária no município do Rio Grande, Rio Grande do Sul (RS), Brasil.

O Trabalho Técnico Social - TTS constitui-se em uma prática social, outorgada pelos acordos de investimento internacional e desenvolvida no Brasil e nos projetos sociais, regida pela legislação brasileira, mais especificamente pela lei de número 10.257 de 2001, Estatuto das Cidades (Planejamento participativo e função social da propriedade), onde este trabalho passa a ser item de investimento recomendável a partir de 2000 e obrigatório a partir de 2006.

Neste traçado documental, explicita-se a ação técnica voltada para mitigar os impactos gerados no processo de reassentamento dos moradores de áreas urbanas irregulares para condomínios devidamente regularizados e urbanizados, no contexto da política de Habitação de Interesse Social. Tal política é desenvolvida com populações das periferias urbanas que ocupam áreas sem saneamento básico, em condições de vulnerabilidade 
socioambiental, tais como: eventos extremos a exemplo de inundações e alagamentos, bem como a recuperação de áreas para empreendimentos industriais, ou de instalação de infraestrutura de transporte ou de geração e transmissão de energia.

Nestes contextos, a atuação do Trabalho Técnico Social deve constituirse como processo educativo que deve promover a participação e a construção da cidadania, que neste caso também é ambiental. É importante ressaltar que o trabalho técnico social é conduzindo por profissionais como sociólogos, assistentes sociais e pedagogos com a responsabilidade de planejar, desenvolver e avaliar os processos de organização comunitária no campo das políticas sociais.

Para o desenvolvimento deste artigo partimos de duas premissas fundamentais. A primeira é o entendimento que o processo educativo se constitui por práticas sociais que possibilitam o espaço político de participação na gestão e no controle social na implementação de políticas públicas de habitação social.

A segunda trata da pedagogia crítica e emancipadora, preconizada por Paulo Freire e balizadora da Educação Popular; entendida como prática social emancipatória e construtora de autonomia dos sujeitos frente a sua ação no mundo. Tais premissas justificam a compreensão de que o desenvolvimento das políticas sociais, quando comprometidas com a participação e a diminuição das injustiças socioambientais, necessita de processos educativos que tenham em sua intencionalidade e metodologia o encontro com uma perspectiva de educação ambiental crítica e popular.

Dessa forma compreender de que forma a Educação Ambiental Crítica e Transformadora pode contribuir para o desenvolvimento do Trabalho Técnico Social é fundamental.

A Educação Ambiental, enquanto práxis transformadoras tem papel importante na busca da construção coletiva de processos sociais. Para tanto há que se considerar os aspectos ontológicos do educador/pesquisador. A sensibilidade, a alteridade, a empatia a capacidade de reconhecer as lideranças locais, ou seja, todas as características básicas do educador ambiental, popular e freireano. 
É importante mencionar que de acordo com Paulo Freire (1979) não se pode superar a ingenuidade presente no senso comum sem assumir tais preceitos. Neste aspecto, ao superar a ingenuidade que condiciona o modo pelo qual o sujeito se relaciona com o mundo, ampliamos as possibilidades de intervir na formação de sujeitos que se encontram em situação de injustiça socioambiental. Por meio de estratégias fundamentadas no diálogo, e no exercício de reflexão-ação-reflexão, articula-se no processo educativo conteúdo e forma, como categorias centrais para o desenvolvimento de práticas autônomas, e ampliação da consciência critica.

A pedagogia freiriana entende que para transformar o mundo é necessário se apropriar do mesmo. Dessa forma, o esforço de análise neste artigo busca o aprofundamento das questões teórico/práticas em torno da Educação Ambiental na práxis do trabalho técnico social, inserido no contexto de conflitos socioambientais no processo de expansão portuária e reassentamento habitacional das famílias do Bairro Getúlio Vargas (BGV), no Município do Rio Grande/RS.

Assim, nosso ponto de partida para as reflexões futuras, situa-se na compreensão de que os problemas enfrentados por estas populações não são estáticos e nem fadados à permanência. Na área da Educação Ambiental, situamos a fundamentação teórica critica e Transformadora de viés emancipatório e popular, segundo o qual a realidade não está dada, ela vai se formando e se construindo através das posturas dos agentes sociais, das populações envolvidas, de seus dramas, sonhos, anseios, disputas, emoções e conflitos e das condições materiais concretas em que a vida é produzida, ou seja, pela práxis dos sujeitos envolvidos.

\section{A EXPANSÃO PORTUÁRIA E O PROCESSO DE REASSENTAMENTO DAS FAMÍLIAS RESIDENTES NO BAIRRO BGV E A PROBLEMÁTICA DE INJUSTIÇA SOCIOAMBIENTAL}

Os elementos históricos que constituem as características do município de Rio Grande nos auxilia na compreensão da relação deste município com o Porto, bem como o impacto desta no cotidiano dos moradores do BGV. Neste movimento, observa-se que o BGV é (re)constituído por delimitações geográficas ocorridas no processo de expansão do capital, no qual, dentre os 
impactos socioambientais, evidencia-se a remoção das famílias localizadas nas áreas de interesse - como impacto de maior promoção da injustiça socioambiental ${ }^{4}$.

Retomando a análise histórica da cidade do Rio Grande, observamos que positiva ou negativamente, a cidade constitui-se sobre impactos socioambientais oriundos das atividades portuárias. Os estudos realizados sobre este tema denunciam que o movimento de expansão portuário é prática constante na realidade do município e apontam a atenção para o processo de expansão realizado na década de 1970. A partir do qual, podemos evidenciar significativas semelhanças com a atualidade.

Em linhas gerais registra-se que a cidade do Rio Grande possui uma geografia privilegiada no que se refere ao processo de expansão urbana. 0 município caracteriza-se por sua localização em uma região de restinga, na qual além do porto representar um dos principais elementos de pujança, não necessariamente se apresenta como principal força de desenvolvimento no cotidiano das famílias que compõem a classe trabalhadora no seu entorno, e na cidade. Situação, que justifica a compreensão de que nos municípios portuários existe uma presença mais intensa do capitalismo, tendo como resultado o acirramento das desigualdades socioambientais, colocando muitas famílias em situação de extrema vulnerabilidade ambiental.

A demarcação histórica nos permite afirmar que o desenvolvimento das atividades portuárias no município, operam a partir da segunda metade do século XX - como elemento chave - no processo de deslocamentos das famílias para as áreas adjacentes a tal empreendimento; bem como, para a constituição do BGV - que resulta essencialmente do crescimento operacional do Porto e do processo de industrialização correlacionado.

\footnotetext{
${ }^{4}$ Injustiça Socioambiental é um termo construído no contexto da crise ambiental, e evidenciado na luta dos movimentos sociais, para demarcar a necessidade de construirmos uma estrutura societária capaz de garantir a toda humanidade o direito ao meio ambiente ecologicamente equilibrado, neste processo a bandeira de luta constitui-se por Justiça Ambiental. Para Acselrad (2005, p. 224) Justiça Ambiental é, [...] uma noção emergente que integra o processo histórico de construção subjetiva da cultura dos direitos no bojo de um movimento de expansão semântica dos direitos humanos, sociais, econômicos, culturais e ambientais. Na experiência recente, a justiça ambiental surgiu da criatividade estratégica dos movimentos sociais, alterando a configuração de forças sociais envolvidas nas lutas ambientais e, em determinadas circunstâncias, produzindo mudanças no aparelho estatal e regulatório responsável pela proteção ambiental.
} 
O historiador riograndino Francisco das Neves Alves (2008), publicou uma obra chamada Porto e Barra do Rio Grande: História, memória e cultura portuária, obra está de dois volumes e faz um apanhado histórico do porto do Rio Grande e suas relações com o município. Para o autor, a década de 1970 foi crucial para o crescimento do município do Rio Grande e para o desenvolvimento comercial do porto riograndino, devido a política de industrialização, que no regime civil militar brasileiro, a exportação tornou-se um objetivo importante para economia do país. Para viabilizar o proposito, foi preciso modernizar a estrutura portuária a fim de dotar o Brasil de condições de competitividade no cenário comercial da segunda metade do século passado.

Este movimento, segundo o prisma da teoria marxista, está articulado a acumulação do capital a partir da década de 70 do século XX passou por um processo de acumulação flexível da mais-valia, ou seja, a produção de excedente antes restrita ao ambiente local, alcança uma escala global e planetária, sendo que as economias entre as nações se tornam um pouco mais integradas e interdependentes do ponto de vista econômico (Harvey, 1993).

Neste sentido, corroboramos com Domingues (1997) ao compreender o porto como um grande símbolo desta nova fase do sistema capitalista. Logo, por mais que houvesse uma resistência no município do Rio Grande, que manifestasse interesse contrário ao modelo de desenvolvimento proposto - a expansão portuária certamente não seria impedida.

Tal compreensão nos coloca diante do conceito de injustiça ambiental, construído pelos movimentos sociais no enfrentamento das desigualdades produzidas pelas atividades de produção no sistema capitalista e nos desafia a pensar sobre a seguinte questão: De que forma tal expansão atinge a população local, especialmente a comunidade do bairro Getúlio Vargas?

Sobre esta interrogação, na análise dos documentos da época podemos perceber que apesar dos destaques registrados na imprensa local na década de 1970, bem como nos dias atuais - não encontramos referências bibliográficas com potencial para realizarmos um estudo comparativo entorno da remoção das famílias, nos possibilitando apenas o registro de algumas percepções e categorias que se articulam como ponto de partida para análise do processo de remoção das famílias, na atualidade.

Desta forma, para além dos relatos obtidos diretamente com familiares e 
pessoas que vivenciaram a remoção nessa década, utilizamos neste trabalho registros e reflexões construídos por Diego Mendes Cipriano, em trabalho intitulado O Bairro Getúlio Vargas e a Grande Faxina dos Anos 70: A Remoção de Moradias e Consequências Socioambientais na Expansão Portuária (Rio Grande- $R S$ ).

Para Cipriano,

A remoção de moradias liberaria espaços a abertura, de rua, a construção de silos e armazéns e a edificação dos próprios estabelecimentos portuários industriais necessários aos grupos econômicos que aí poderiam se instalar. Para o Porto de Rio Grande, era uma oportunidade clara e indispensável ao investimento, movimentação comercial e a ampliação das exportações. (Cipriano, 2013, p. 5).

Seguindo os estudos do autor, podemos inferir que a cidade de Rio Grande passou por um processo de transformação urbana, na qual as pessoas que sofreram o processo de remoção não tiveram seus direitos básicos respeitados, pois foram obrigadas a abandonar suas casas, sendo submetidas ao deslocamento para locais longínquos do Bairro Getúlio Vargas.

Em meados dos anos 2007, a exatos trinta e sete anos depois, 0 município foi novamente submetido a um projeto de expansão portuária, que tem por objetivo a construção de uma avenida com o objetivo de ligar a Rua Dom Pedro II à BR-392. Para tal empreendimento - que é uma exigência dos padrões internacionais com relação ao tráfego de veículos ${ }^{5}$ e visa expandir o acesso ao Porto- foi necessário, no ano de 2016 executar a remoção de residências de uma área considerável oriunda de processos de ocupação junto ao muro do Pátio Automotivo do Porto e arredores.

Proposição que já não se enquadra mais no simples processo de deslocamento de pessoas, exigindo da instituição proponente 0 reconhecimento dos sujeitos diretamente atingidos, e a implementação do Projeto considerando a constituição de 1988, na qual está previsto o direito à soberania; a cidadania; e, a dignidade da pessoa humana.

\footnotetext{
${ }^{5}$ Segundo Souza (2011, p. 61): "o projeto de expansão portuária no Bairro Getúlio Vargas prevê a construção de uma avenida junto ao muro oeste do pátio automotivo do Porto Novo, ligando a Rua Dom Pedro II até a BR-392 formando um anel viário com a rua Honório Bicalho, atendendo exigências internacionais de segurança e melhorarias do tráfego de veículos na área".
} 
Buscando atender a outorga destes direitos, é que o Porto ${ }^{6}$ em parceria com o Governo Federal e o poder executivo local, através do Programa de Aceleração do Crescimento (PAC) - Intervenção de Favelas do Governo Federal estão em fase de conclusão e entrega para os moradores os Conjuntos Habitacionais BGV I e BGV II.

Estas estruturas de habitação apresentam a capacidade de abrigo de 290 famílias, e foram construídas com finalidade de diminuir o impacto sobre as mesmas - uma vez que foram deslocadas dentro do mesmo bairro. Ainda, com a responsabilidade de auxiliar na reorganização da vida e da cultura destas famílias - dentre as metas do Programa está proposto à intervenção e trabalho do Centro de Referência de Assistência Social (CRAS), que terá uma sede dentro do condomínio BGV I e da Universidade Federal do Rio Grande (FURG), que realizará no período de 15 meses acompanhamento às famílias, com uma equipe interdisciplinar e devidamente capacitada para 0 desenvolvimento do Trabalho Técnico Social (TTS - PAC BGV).

Ao analisarmos os relatórios de cadastro das famílias, observamos que há um predomínio de mulheres na comunidade do BGV, sendo grande parte delas solteiras e divorciadas. Constatamos também que grande parte da população do bairro estudado é pobre e muitas das pessoas vivem em condições econômicas adversas e de miserabilidade.

Nesta situação, é preciso que diferenciemos a pobreza da miséria. Ambas são frutos de um modelo injusto de distribuição de renda, no qual alguns grupos vivem em condições adversas e não conseguem obter a quantidade de renda necessária para uma existência digna, condição que de

\footnotetext{
${ }^{6}$ Quando nos referimos ao Porto, neste artigo estamos tratando do empreendimento em toda sua complexidade de atividades que compreende toda extensão de atuação do Porto velho, área industrial e Porto Novo. Cabe registrarmos que a "Superintendência do Porto de Rio Grande - SUPRG - Autarquia Estadual vinculada à Secretaria da Infraestrutura e Logística do Estado do Rio Grande do Sul, criada pela lei 10.722 de 18 de janeiro de 1996, tem por incumbência administrar o Porto do Rio Grande, na qualidade de executor, da concessão da União ao Estado, como autoridade portuária executiva, coordenando e fiscalizando as diversas entidades atuantes no Porto Organizado, nos termos da Lei Federal no 8.630 , de 25 de fevereiro de 1993. Exploração e administração do Porto do Rio Grande, na forma do Convênio de Delegação № 001 - PORTOS/97, firmado pelo Governo Federal com o Estado do Rio Grande do Sul em 1997, bem como as de planejar a política portuária, estudando, melhorando e conservando os canais de acesso do Porto do Rio Grande. Destacamos a conservação dos Molhes da Barra, canal de acesso ao Porto Novo e a manutenção de todo sistema hidroportuário do Porto do Rio Grande". (conteúdo de apresentação da SUPRG, disponível no site: http://www.portoriogrande.com.br/site/autoridade_portuaria_apresentacao.php acessado em 28/10/2018)
} 
um lado reafirma a necessidade de intervenção do Estado na garantia dos direitos fundamentais de todos os seres humanos, e de outro manifesta a dura face da desigualdade social em que estes sujeitos se encontram submetidos.

Neste cenário, os desafios, as injustiças e as responsabilidades que se apresentam no cotidiano das famílias em situação de vulnerabilidade, manifestam a necessidade de pensarmos o Trabalho do técnico social, não como uma ação imprescindível à garantia dos direitos dos sujeitos injustiçados pelo processo de expansão. Pois, seguramente seria precipitar-se diante da correlação de forças postas na conjuntura - que exige-nos compreender que os interesses que representam a força do capital internacional, nas condições atuais, constituem-se mais fortes do que a mobilização pontual, das famílias diretamente atingidas pelo ônus resultante.

Porém, compreender o limite não significa desconsiderar o horizonte, e, é nesta perspectiva que o trabalho técnico social, em especial na dinâmica da educação ambiental transformadora pode ousar e até mesmo surpreender na construção do que Paulo Freire, anuncia como o desafio da construção do inédito viável.

\section{0 \\ TRABALHO \\ TÉCNICO \\ SOCIAL: PERSPECTIVASTEÓRICO/METODOLÓGICAS NO PROCESSO DE
REASSENTAMENTO DAS FAMÍLIAS NO BAIRRO GETÚLIO VARGAS}

No Brasil, o trabalho técnico social começa a se tornar evidente na década de 30 do século $X X$, período no qual, um mutirão de trabalhadores pobres nas principais cidades brasileiras decidiram ocupar loteamentos e construir suas casas. Estes loteamentos em sua grande maioria eram ilegais e não receberam do Estado a devida assistência no que se refere a infraestrutura. O resultado disso foi à degradação ambiental, problemas de saúde e dificuldades de acesso por parte dos habitantes desse local de condições mínimas de cidadania.

Nos anos 60, com a efervescência das discussões das reformas de base - a questão da cidadania, destacando-se o aspecto habitacional tornam-se assuntos da agenda nacional - e o Estado brasileiro reconhece a desigualdade do Brasil e o processo de urbanização acelerada presente no país. Decide-se que é necessário intervir para corrigir tal dívida histórica. Processo que é interrompido - com o golpe 64 - que acaba por instalar um regime civil militar, 
inicialmente provisório que acabou se estendendo por 21 anos.

Ao término do regime militar, os ideais de resgate da cidadania e da valorização da moradia voltam à agenda nacional - em outra condição. Pósregime, o campo de estudos das ciências sociais, os movimentos sociais e os trabalhadores, apresentavam um acumulo sobre o papel do Técnico social, que marca a construção de novas finalidades e metodologias para o trabalho.

Ainda, mesmo com todo este contexto e com o impulso de pesquisas voltadas a habitação e a utilização do trabalho técnico social - o quadro de déficit habitacional do país ainda é grande. Atribui-se a esta situação, a forte inflação dos anos 80, que aliada a incapacidade fiscal dos gestores públicos, contribuiu e muito, para a ineficiência da articulação de políticas públicas. Processo, no qual evidencia-se que as populações mais pobres acabaram mais prejudicadas.

Segundo Lizete Carvalho (2011) o Trabalho Técnico Social (TTS) tem se tornado uma metodologia cada vez mais utilizada no Brasil, dado ao seu aspecto urbano. O processo de urbanização brasileiro é curioso e instigante, pois em menos de cinquenta anos, o Brasil deixou de ser um país rural para se tornar um país urbano, com mais de $80 \%$ de sua população vivendo nas cidades.

Ainda para autora, o processo técnico social alcança relevância no governo Lula, a partir da criação do Ministério das Cidades no ano de 2003, mas principalmente sua consolidação com o Plano de Aceleração do Crescimento (PAC) em 2007 e com o Programa Minha Casa, Minha Vida no ano seguinte. Neste movimento, compreende-se que a metodologia de trabalho deste profissional caracteriza-se por alguns aspectos, sendo eles: 1) Enfoques Interdisciplinares em sincronia com a obra ou com as obras que devem ser realizadas; 2) Levantamento de dados e informações que caracterizavam a situação local; e, 3) Uma proposta de intervenção onde os sujeitos da comunidade que sofrerá a intervenção tenham direito a participar das decisões e vivenciá-las na prática.

Para Barbosa (2011), o Trabalho Técnico Social pode ser realizado por um assistente social ou por um profissional de outra área desde que o mesmo esteja munido de interesse em participar da comunidade estudada, possua um diário de campo, acompanhe a realidade da comunidade e tenha consciência 
que nunca resolverá o conflito em si do local onde atua, mas que servirá como ferramenta que garantirá a efetivação da política pública na área de habitação.

No caso particular, do processo de reassentamento das famílias, o trabalho do técnico social, segundo a Caixa Econômica Federal - entidade financiadora do projeto,

\begin{abstract}
O Trabalho Técnico Social é o conjunto de ações que visam promover a autonomia e o protagonismo social, planejadas para criar mecanismos capazes de viabilizar a participação dos beneficiários nos processos de decisão, implantação e manutenção dos bens/serviços, adequando-os às necessidades e à realidade dos grupos sociais atendidos, além de incentivar a gestão participativa para a sustentabilidade do empreendimento. As diretrizes para elaboração e implantação do TTS são definidas pelo Ministério das Cidades, cabendo à CAIXA apoiar os entes públicos na formulação dos projetos e acompanhar e atestar sua execução. (Caixa Econômica Federal, 2011, p. 76)
\end{abstract}

Assim, objetivando atender a demanda citada pela caixa, o planejamento do trabalho está organizado para desenvolver-se em três eixos centrais: Mobilização e Organização Comunitária; Geração de Trabalho e Renda e Educação Sanitária e Ambiental. Neste processo, cabe registrarmos que mesmo que os três eixos exijam metodologias diferenciadas, compreendemos que eles acontecem de forma articulada, possibilitando 0 exercício deste artigo - que estrutura-se na proposição de aprofundamento das questões teórico/práticas entrono do processo educativo comprometido com a superação das questões socioambientais que condicionam os sujeitos à situação de vulnerabilidade no contexto da realidade em que estão diretamente envolvidos.

\title{
A EDUCAÇÃO AMBIENTAL TRANSFORMADORA NA PRÁXIS DO
} TRABALHO TÉCNICO SOCIAL: UM ENCONTRO COM A TEORIA CRÍTICA E FREIREANA

O diálogo entre a Educação Ambiental transformadora e a Educação Libertária de Paulo Freire no contexto do trabalho técnico social, articula-se no período histórico em que esta área de atuação se insere no território brasileiro. No período, entre os anos de 1930 a meados dos anos 1960, vivenciamos no país um significativo movimento de reformas e avanço das pautas populares no centro da agenda governamental, que se encontra em acelerado processo de 
urbanização e industrialização, conforme já abordado.

Neste contexto, Paulo Freire junto aos intelectuais da educação e militantes dos sindicatos e movimentos sociais, acumulam nas práticas de educação popular, perspectivas metodológicas e métodos que redimensionam o trabalho técnico social, a partir de uma perspectiva libertária.

$\mathrm{Na}$ prática, compreendia-se o trabalho técnico social amparado pela pedagogia social - que no Brasil, devido a influência das escolas libertárias construía-se num movimento que, procura responder perguntas a respeito do processo de integração do indivíduo à sociedade, tanto dos pontos de vista teórico como prático (Otto, 2009).

Logo, no trabalho sociala pedagogia opera nas questões existenciais sobre valores, termos de desenvolvimento pessoal, construção da identidade e do crescimento humano (Otto, 2009). A contribuição da teoria crítica e freireana nesta área, - situa-se em combinar a pedagogia do oprimido aos processos de integração do indivíduo, com a intencionalidade comprometida com emancipação.

Neste movimento, o trabalho técnico social, em especial a partir dos anos de 1980 afirma-se enquanto processo educativo, reduzindo a dimensão assistencialista e imediatista que compunham as práticas exercidas pelo Estado, ao tempo que se apropriava dos métodos e categorias estruturadas na prática da educação popular.

Através da Pedagogia do Oprimido, Paulo Freire (1987) afirma que toda ação educativa que não se pretende bancária - constitui-se como processo formativo dos sujeitos e se desenvolve articulado a um movimento onmilateral ${ }^{7}$, dialógico e essencialmente mediado pelas questões e estruturas que montam e remontam o mundo real. Ou seja, toda educação acontece entre os sujeitos que se relacionam entre si, mediados pelo ambiente que os forma ao tempo que pelos próprios sujeitos é formado.

No cotidiano de reassentamento das famílias no Bairro Getúlio Vargas, as experiências formativas são desenvolvidas a partir deste movimento

\footnotetext{
7 "Omnilateral é um termo que vem do Latim e cuja a tradução literal significa "todos os lados ou dimensões". Educação omnilateral significa, assim, a concepção de educação ou de formação humana que busca levar em conta todas as dimensões que constituem a especificidade do ser humano e as condições objetivas e subjetivas reais para seu pleno desenvolvimento histórico (FRIGOTTO, 2012, p. 265)."
} 
teórico/prático. No qual, dentre o conteúdo do diálogo encontra-se 0 compromisso com o desvelamento da realidade, e a evidência das situações limites que condicionam os sujeitos em processo de remoção.

Desta forma, evidenciamos através do diálogo a compreensão seres inconclusos e por isso, aprendentes em constante movimento de desvelamento desta sociedade. Processo que segundo Freire (1987), ocorre num movimento de ação-reflexão-ação, baseado no comprometimento com o amadurecimento da leitura de mundo de todos sujeitos que se encontram envolvidos na ação educativa. $\mathrm{Na}$ realidade específica deste trabalho, o diálogo é tecido ao objetivar a compreensão sobre os condicionamentos postos tanto para 0 exercício da cidadania, quanto para garantia dos direitos fundamentais do coletivo de famílias em situação de reassentamento.

Esta perspectiva teórica/metodológica se articula ao campo da Educação Ambiental transformadora, que se coloca como elemento chave no processo de superação das situações limites. Sobre esta é importante, compreendermos a ênfase nas reflexões de Guimarães (1996) ao denunciar que o ambiente no currículo da educação, só é necessário, por que, a educação ainda não dialoga sobre estas questões. Ou pelo menos, ainda mantem no processo educativo uma compreensão cartesiana fundamentada na racionalidade que nos mantem subordinados a lógica eurocêntrica - que outorga aos senhores do Capital, o domínio, a exploração e a destruição de toda natureza viva.

Porém, no contexto da educação não formal, a educação ambiental é fundada no pé da comunidade sob as bases da injustiça ambiental - logo, no território popular - a educação no ambiente assume-se eminentemente enquanto ato político e como já vimos, constitui-se como instrumento de desvelamento da realidade que tem por conteúdo de diálogo as situações limites vivenciadas pelos sujeitos envolvidos.

Para Loureiro (2004) a educação ambiental é transformadora e emancipatória quando empodera civicamente os cidadãos, capacitando-os criticamente no processo de atuação em sua própria realidade. Ainda para o autor a Educação Ambiental Emancipatória exige uma abertura a temas relacionados ao cotidiano e a experiência de vida de cada um dos cidadãos.

Assim, afirmamos diante do exposto, que perspectiva da educação 
popular articulada metodologicamente a prática do trabalho técnico social potencializa o desenvolvimento da Educação Ambiental crítica e transformadora e emancipatória. E, coloca-se como desafio a construção de um processo formativo que define práxis revolucionária (Vázquez, 2007), que visa horizonte emancipatório (Marx, 1989), que busca transformar o status quo (Loureiro, 2012), que luta por justiça ambiental (Acselrad, 2005) - articulandose na coletividade para reconstrução do sujeito consciente, e, capaz de intervir na sociedade com ciência e domínio das ferramentas necessárias à construção de alternativas.

\section{CONSIDERAÇÕES FINAIS}

O desdobramento das reflexões que apontamos ao longo do texto fazem parte da Dissertação de Mestrado, intitulada Olhares sobre os Processos do Trabalho Técnico Social, junto aos moradores reassentados nos conjuntos residenciais Getúlio Vargas I e II na perspectiva da Educação Ambiental Transformadora, desenvolvida no Programa de Educação Ambiental desta Universidade. Desta forma, o recorte reflexivo apresentado neste artigo apresenta-se como instrumento provocativo, sem nenhuma pretensão de concluir, compreendemos nestas reflexões não só a importância de dialogar sobre os fundamentos que compreendem a dimensão ambiental e política no trabalho do técnico social.

Neste movimento, observamos que o processo de educação ambiental, está articulado a defesa do princípio de indissociabilidade entre corpo-mentesociedade-natureza, e que ao fundamentar-se na proposição do diálogo freireano constitui-se como instrumento importante no processo de superação das situações limites.

A revisão bibliográfica, desenvolvida neste artigo também nos permite compreender que o Trabalho Técnico Social (TTS), quando comprometido com a Educação Popular na perspectiva de Paulo Freire (1987), constitui-se como um diferencial no processo de emancipação dos sujeitos. Assumindo uma dinâmica processual, que ocorre sob as bases da autonomia relativa e de uma educação ambiental, que segundo Loureiro (2012) reconhece o conflito socioambiental, e os diferentes interesses que emergem no campo do trabalho, estruturando-se em forma e conteúdo de acordo com as necessidades que 
emergem ao longo da ação educativa.

\section{REFERÊNCIAS BIBLIOGRÁFICAS}

ACSELRAD, Henri. "Justiça Ambiental In: Encontro e Caminhos: formação de educadoras (es) ambientais e coletivos educadores". 2005. P.217 228.

www.mma.gov.br/estruturas/educamb/_arquivos/encontros.pdf.

FREIRE, Paulo. Pedagogia do Oprimido. 17ª . Ed. Rio de Janeiro: Paz e Terra: 1987.

FRIGOTTO, Gaudêncio. "Educação Omnilateral. In:Dicionário da Educação do Campo". 2a. Ed. Rio de Janeiro, São Paulo: Escola Politécnica de Saúde Joaquim Venâncio. Expressão Popular. 2012. P. 265-271.

GRÜN, Mauro. Ética e Educação Ambiental: a conexão necessária. Coleção Magistério: Formação e Trabalho Pedagógico. Campinas, SP: Papiros, 1996.

LAYRARGUES, Philippe P. "Para onde vai a educação ambiental? 0 cenário político-ideológico da educação ambiental brasileira e os desafios de uma agenda política crítica contra-hegemônica". In: Revista Contemporânea de Educação $\mathrm{N} \cong 14$ - agosto/dezembro de 2012.

LOUREIRO, Carlos Frederico B. Trajetórias e fundamentos da educação ambiental. 4ª . Ed. São Paulo: Cotez, 2012.

MARX, Karl. A questão judaica. 2ạ . Ed. Tradutor: Artur Morão. [s.I]: LusoSofia:Press, 1989.

OTTO, Hans-Uwe. “Origens da Pedagogia Social”. In. SILVA, João R.; NETO, Clemente S.; MOURA, Rogério A. (ORG's). Pedagogia social. São Paulo: Expressão Popular e Arte Editora. 2009

VÁZQUÉZ, Adolfo S. Filosofia da práxis. "Bueno Aires: ConsejoLatinoamericano de ciências Sociales-CLACSO". São Paulo: Expressão Popular, 2007.

LOUREIRO, C.F. Trajetória e Fundamentos da Educação Ambiental. São Paulo: Cortez, 2002.

Caixa Econômica Federal, Manual Normativo Regulamento do Trabalho Técnico Social.AE 097 V21, 2011, p. 76.

CIPRIANO, Diego. O Bairro Getúlio Vargas e a Grande Faxina dos Anos 70: Remoção de Moradias e Consequências Socioambientais na Educação Portuária. Rio Grande: Furg, 2013.

CARVALHO, Lizete. "Trabalho Técnico Social $X$ Meio Ambiente nos Programas Habitacionais Brasileiros". Revista Eletrônica em Gestão, Educação e Tec. Ambiental. Carvalho, V (4) número 4 p. 593-607, 2011. 
DOMINGUES, M.R.V. "Os conflitos de uso socioeconômico ambientais e o processo de caotização do espaço urbano local". Informativo Searg. Rio Grande, marçol abril de 1995.

HARVEY, David. A produção capitalista do espaço. São Paulo: Anablume, 2005.

FREIRE, Paulo. Extensão ou Comunicação.Rio de Janeiro: Editora Paz e Terra, 1975.

NEVES, Francisco Das. Porto de Rio Grande Uma Secular Aspiração que tornou-se realidade. Rio Grande V1 e V2: Furg, 2008. 